\title{
Exerted Stresses from Loading Distal -Extension Removable Partial Denture with Different Occlusal Rest Position A Finite Element Stress Analysis Study \\ Souza Abdul Aziz \\ Prof.
}

Imad Aljoubouri

Prof.

Wasmaa S. Mahmood

Assist prof.

\begin{abstract}
The treatment of distal extension base removable partial denture has long been the dilemma of many Prosthodontists, since the support for this type of restoration is based on two functionally different systems, the teeth and associated periodontal membrane and the edentulous ridges. So one of their most elusive goals were to finish the prosthesis by utilizing both systems of support without exposing the tissues to undue stresses which might lead otherwise to bone resorption.

Material and method: A two-dimensional finite element analysis method was used to assess the stress distribution on supporting structure where different rest position, including mesial-occlusal rest, distal-occlusal rest, and mesio-distal occlusal rest.

The $X$, and $Y$ coordinate for each node of the model was transferred to the ANSYS program, a load of 10MP was used in this study, where each of the models was subjected to load distributed on the saddle area.
\end{abstract}

Results: Von Mises stress values revealed that, mesial rest produces less stress concentration,

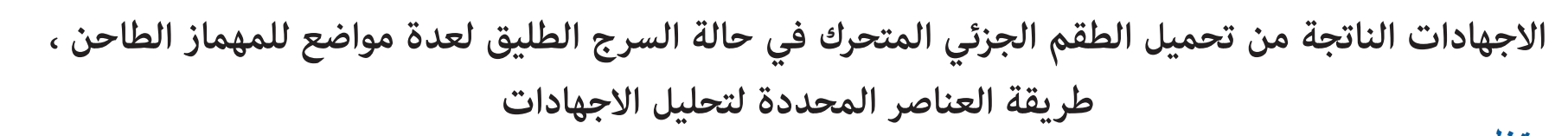

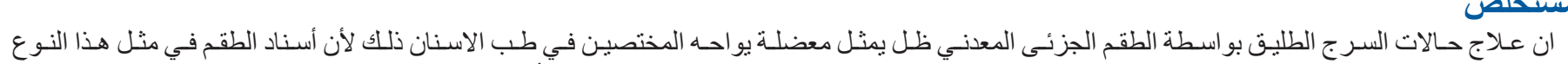

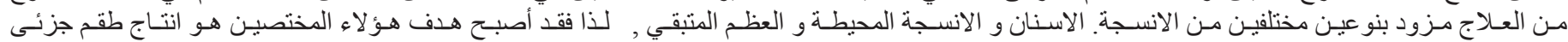

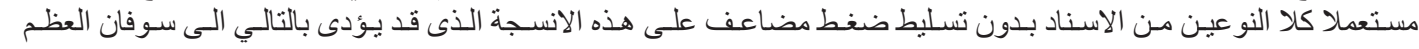

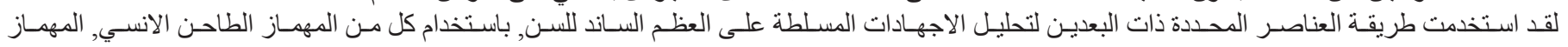

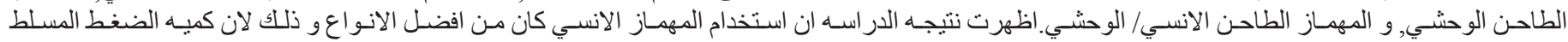

\section{INTRODUCTION}

The treatment of distal extension base removable partial denture has long been the dilemma of many Prosthodontists, since the support for this type of restoration is based on two functionally different systems, the teeth and associated periodontal membrane and the edentulous ridges. So one of their most important goals were to finish the prosthesis by utilizing both systems of support without exposing the tissues to unnecessary stresses which might lead otherwise to bone resorption ${ }^{(1)}$.

One of the dentist's most interesting and thought-provoking situations occurs when treatment requires a rigid prosthetic replacement, which must be compatible with two different kind of support, this situation exists in treatment with distal extension partial dentures, When the functional occlusal load is induced on this kind of partial denture, a rotary movement usually occurs around the fulcrum of the terminal abutment teeth dentures ${ }^{(2)}$.

The ideal situation is most closely approached when the restoration allows the concentrated force of the occlusal load to be collinear with the long axes of the teeth, since the teeth and periodontium are best suited to resist axially directed forces ${ }^{(3)}$.

This is why various components of the removable partial dentures are specifically designed to withstand these forces and the success of prosthesis depends on whether it does this effectively. By success is meant that both comfort and function of the denture are satisfied, as well as "preservation of what remains" Devan $1952^{\prime(4)}$. Kratochvil $1963^{(5)}$ was one of the first researchers to hold the concept of mesial rest position; he found numerous advantages over distal rest placement. The mesial rest will direct forces more perpendicular to the long axes of the tooth, also gingiva adjacent to most posterior tooth is less likely to be pinched with mesial rest.

Thompson et $a l^{(6)}$ used photoelastic model to observe and evaluate the effect of different direct retainer design and occlusal rest position on abutment movement, but it is a quantative and inaccurate method, but the finite element method has superseded other techniques, when was first introduced to the dentistry field in the early seventies, because, stress magnitude can be easily obtained and all types of stress output can be calculated. The computer gives a discription of each piece of the model, where to be placed when 
loaded and how much of a load each component will carry, it is used in vitro investigation method for the examination of the complex mechanical behaviors of prostheses and surrounding structures; It is therefore ideally suited for the present study ${ }^{(7,8,9)}$.

\section{MATERIALS AND METHOD}

A two dimensional strain mesh of the mandibular second permanent premolar with its supporting structures, distal extension RPD, and bone forming part of the mandible.

Three models were prepared for this study; the models were with normal bony support, crown /root ratio $(1 / 2)$

Table (1) represents the symbols and designs of the FEM.

Table (1)

\begin{tabular}{|c|c|}
\hline Symbols & Design \\
\hline D & normal bone support, distal rest. \\
\hline M & normal bone support, mesial rest. \\
\hline MD & normal bone support, mesial-distal rest. \\
\hline
\end{tabular}

For all the above design

A distributed surface pressure on the saddle area, demonstrating (first and second molar), of $10 \mathrm{MPa}$.

After drawing three figures on a graded paper each coordinate both in X, Y were transmitted to the ANSYS program as an input data.
The key points were connected by lines, then connecting these lines created six areas,

$\mathrm{Co}-\mathrm{Cr}$.Alloy, Enamel, Dentine, Periodontal ligament, mucosa, cortical bone, and Cancellous bone.

The proper value of the Young's Modulus,"E" and, Poisson's ratio "V" are shown in Table (2)

Table (2)

\begin{tabular}{|c|c|c|}
\hline Materials & Young's modulus (Mpa) & Poisson's ratio \\
\hline Co-Cr.Alloy & 218000 & $0.33^{(10)}$ \\
\hline Enamel & 84000 & $0.33^{(11)}$ \\
\hline Dentine & 18600 & $0.31^{(11)}$ \\
\hline PDL & 3.45 & $0.45^{(11)}$ \\
\hline Cortical bone & 13000 & $0.3^{(12)}$ \\
\hline Cancellous bone & 1000 & $0.3^{(12)}$ \\
\hline Gold & 99300 & $0.33^{(13)}$ \\
\hline Titanium & 110000 & $0.33^{(13)}$ \\
\hline
\end{tabular}

A fine mesh of the Finite Element model was generated using the quadrilateral 8-node, which is a higher order version of the 2D-4-node element; it provides more accurate results and can tolerate irregular shapes without as much loss of accuracy as shown in figure (1). 


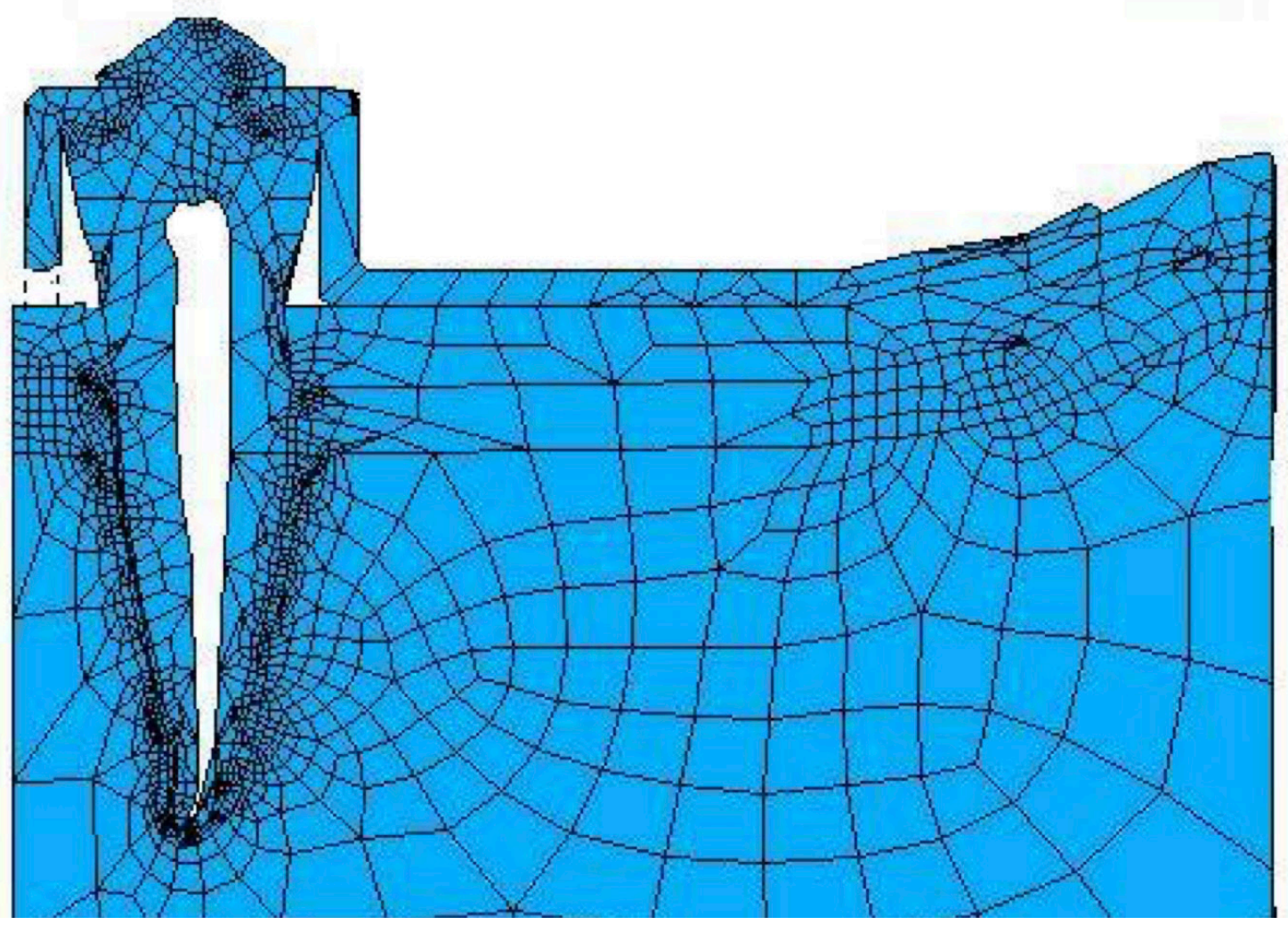

Fig (1) Shows 2-D plain strain mesh in normal bone support

After applying load as described previously, the is represented by the equivalent Von Mises stress at ANSYS program will do the processing of the given selected nodes ${ }^{(10,11,14,15))}$. data, Listing the results; The results of this study

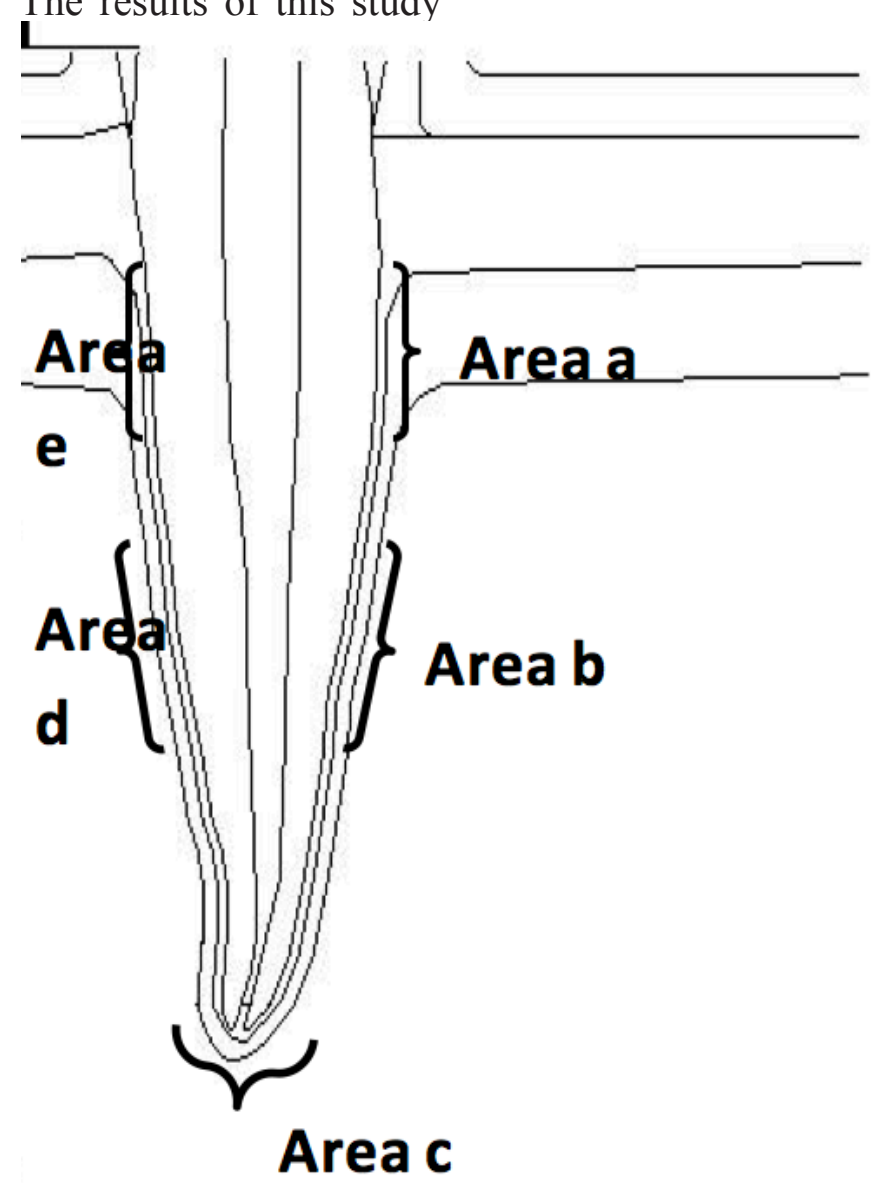

Fig (2): Shows the selected areas for measuring the mean stress values. 


\section{RESULTS}

When external distributed pressure is applied on the saddle area for the three designs (D, M and MD), Table (3) shows no significant difference among the three designs except in (area d) where the mean stress value of MD is the highest followed by $\mathrm{D}$ as shown in figuer (3) and M, where the mesial rest is significantly lower than the distal rest and the mesiodistal rest at $\mathrm{P}>0.01$.

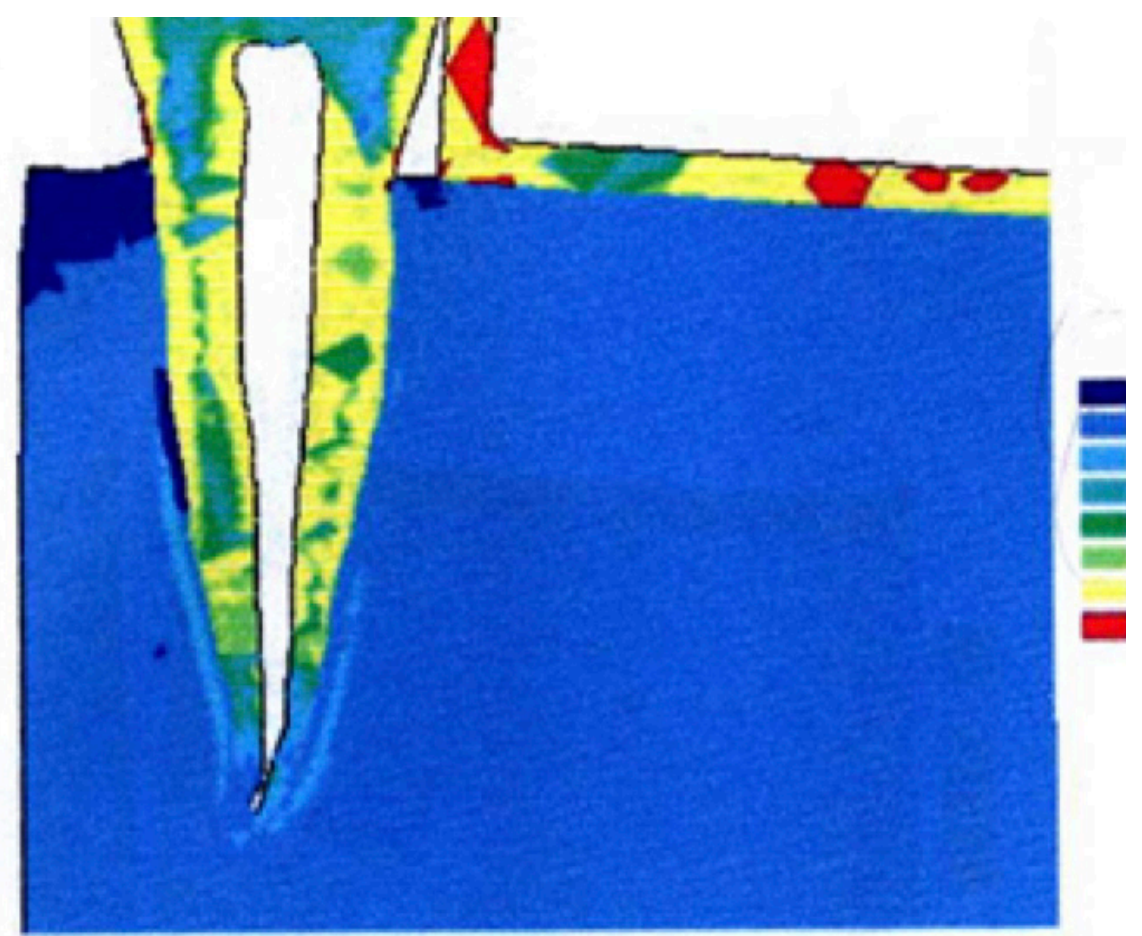

Figuer (3) distribution of the equivalent Von Mises stress contour for distal rest design

Table (3): The comparison among the three designs (D, M, and MD) when pressure is applied on the saddle area.

\begin{tabular}{|c|c|c|c|c|c|c|c|}
\hline \multirow[t]{2}{*}{ Groups } & Design & $\begin{array}{c}\text { Mean Stress } \\
\mathrm{MPa}\end{array}$ & SD & 95 C.I. & Minimum & Maximum & \\
\hline & & & & Lower bound & Upper bound & & \\
\hline \multirow[t]{3}{*}{ (Area a) } & $\mathrm{D}$ & 5.866 & 1.310 & 2.610 & 9.123 & 4.35 & 6.64 \\
\hline & M & 4.610 & 1.302 & 1.373 & 7.846 & 3.29 & 5.90 \\
\hline & MD & 5.803 & 0.958 & 3.421 & 8.184 & 4.82 & 6.74 \\
\hline \multirow[t]{3}{*}{ (Area b) } & $\mathrm{D}$ & 14.336 & 0.975 & 11.912 & 16.759 & 13.3 & 15.2 \\
\hline & M & 16.712 & 1.619 & 12.688 & 20.736 & 14.865 & 17.890 \\
\hline & MD & 15.666 & 2.384 & 9.743 & 21.590 & 13.235 & 18.001 \\
\hline \multirow[t]{3}{*}{ (Area c) } & $\mathrm{D}$ & 15.781 & 6.055 & 6.145 & 25.416 & 9.44 & 21.0 \\
\hline & M & 14.139 & 7.144 & 2.771 & 25.507 & 7.47 & 24.3 \\
\hline & MD & 15.114 & 8.989 & 0.810 & 29.419 & 7.66 & 27.8 \\
\hline \multirow[t]{3}{*}{ (Area d) } & $\mathrm{D}$ & 30.611 & 1.451 & 27.005 & 34.217 & 29.7 & 32.3 \\
\hline & M & 21.766 & 1.449 & 18.165 & 25.368 & 20.6 & 23.4 \\
\hline & MD & 35.202 & 1.718 & 30.934 & 39.470 & 33.4 & 36.9 \\
\hline \multirow[t]{3}{*}{ (Area e) } & $\mathrm{D}$ & 5.344 & 1.577 & 1.424 & 9.263 & 4.09 & 7.12 \\
\hline & M & 2.743 & 1.993 & -2.208 & 7.694 & 1.21 & 5.00 \\
\hline & MD & 5.009 & 2.479 & -1.149 & 11.167 & 2.32 & 7.20 \\
\hline
\end{tabular}


ANOVA

\begin{tabular}{|c|c|c|c|c|c|c|}
\hline & & $\begin{array}{l}\text { Sum of } \\
\text { squares }\end{array}$ & $d f$ & $\begin{array}{l}\text { Mean } \\
\text { square }\end{array}$ & $F$ & Significant \\
\hline \multirow{3}{*}{ (Area a) } & Between groups & 3.007 & 2 & \multirow{3}{*}{$\begin{array}{l}1.503 \\
1.445\end{array}$} & \multirow{3}{*}{1.040} & \multirow{3}{*}{0.409} \\
\hline & Within group & 8.670 & 6 & & & \\
\hline & Total & 11.676 & 8 & & & \\
\hline \multirow{3}{*}{ (Area b) } & Between groups & 8.509 & 2 & \multirow{3}{*}{$\begin{array}{l}4.254 \\
3.087\end{array}$} & \multirow{3}{*}{1.378} & \multirow{3}{*}{0.322} \\
\hline & Within group & 18.523 & 6 & & & \\
\hline & Total & 27.032 & 8 & & & \\
\hline \multirow{3}{*}{ (Area c) } & Between groups & 5.452 & 2 & \multirow{3}{*}{$\begin{array}{c}2.726 \\
56.172\end{array}$} & \multirow{3}{*}{0.049} & \multirow{3}{*}{0.953} \\
\hline & Within group & 505.545 & 6 & & & \\
\hline & Total & 510.997 & 8 & & & \\
\hline \multirow{3}{*}{ (Area d) } & Between groups & 279.837 & 2 & \multirow{3}{*}{$\begin{array}{c}139.919 \\
2.387\end{array}$} & \multirow{3}{*}{58.618} & \multirow{3}{*}{0.000} \\
\hline & Within group & 14.322 & 6 & & & \\
\hline & Total & 294.159 & 8 & & & \\
\hline \multirow{3}{*}{ (Area e) } & Between groups & 12.012 & 2 & \multirow{3}{*}{$\begin{array}{l}6.006 \\
4.203\end{array}$} & \multirow{3}{*}{1.429} & \multirow{3}{*}{0.311} \\
\hline & Within group & 25.220 & 6 & & & \\
\hline & Total & 37.232 & 8 & & & \\
\hline
\end{tabular}

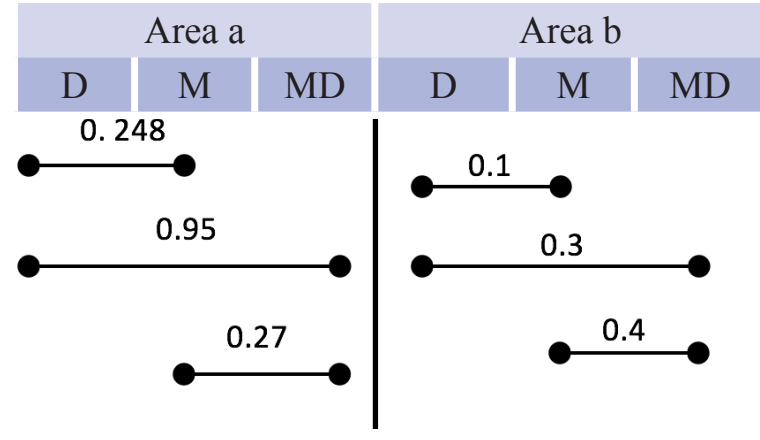

\section{DISCUSSION}

A two- dimensional finite element analysis method is carried out, although tooth is a threedimensional structure, but the use of a 2-D model is also valuable, because of improved performance in terms of element number ${ }^{(16,17)}$.

Where external pressure is applied on the saddle area, the stress is higher in (area d) mesial middle third of root surface than the apical area (area c), this approaches more the normal physiological occlusal force, that stress at the apex is less than on root side, which will subsequently prevent any traumatic load on the apical area which leads to blood vessels strangulation and bone resorption. because the normal physiological axial force applied on unrestored tooth, the internal stresses are distributed evenly around the root, with minimum pressure at the place of entry of the neurovascular supply to the tooth this explain how the blood vessels entering the tooth are not affected by physiological occlusal forces; This is the reason why the bone destruction is always seen on the walls of the socket and almost never around the apex.$^{(18,19)}$
It can be explained that, in mesial rest when load is applied on the saddle, the effort arm will increase, so greater part of the load is carried by the ridge and proportionately less by the tooth, further, since the saddle is farther removed from the fulcrum point (Mesial rest), the stress over the ridge is increased and more evenly distributed in an antero-posterior direction. Also the direction of torquing movement will change in a favorable direction, that is mean in a forward direction which can be supported from the $\operatorname{adjacent}_{\text {tooth }}^{(20,21)}$.

\section{CONCLUSION}

The stress value of mesial rest design was significantly less than the the other designs in the mesial middle third of root surface when pressure is applied on the saddle area.

\section{REFERENCES}

1. Simindokht Zarrati1, Mehran Bahrami, Fatemeh Heidari, Jamal Kashani "Three Dimensional Finite Element Analysis of Distal Abutment Stresses of Removable Partial Dentures with Different Retainer Designs" Journal of 
dentistry 2015;12(6):389-97.

2. HUEY-ER LEE1,2 JU-HUI WU1 CHAU-HSIANG WANG1,2 TING-HSUN LAN1 J E-KANG DU1

"Biomechanical analysis of distal extension removable partial dentures with different retainers "2008 J Dent Sci, 3(3) 133-139

3. Boero E, Forbes W. consideration in design of removable prosthetic devices with no posterior abutment. J Prosthet Dent 1972; 28(3): 253-63.

4. Thomas CJ. The geometry of function of distal extension base removable partial denture designs. J Dent Assoc. South Africa 1996;51:815-18.

5. Kratochvil F. Influence of occlusal rest position and clasp design on movement of abutment teeth. J Prosthet Dent 1963; 13(1): 114-124.

6. Thompson, Kratochvil, Caputo. Evaluation of photoelastic stress patterns produced by various designs of bilateral distal-extension removable partial dentures. J Prosthet Dent 1977; 38(3):261-73.

7. Gharechahi J1, Sharifi E, Aghdaee NA, Nosohian S Finite element method analysis of the stress distribution to supporting tissues in a Class IV Aramany removable partial denture (Part I: the teeth and periodontal ligament). J Contemp Dent Pract. 2008 Sep 1;9(6):65-72.

8. Wakabayashi N1, Ona M, Suzuki T, Igarashi Y. Nonlinear finite element analyses: advances and challenges in dental applications. J Dent. 2008 Jul;36(7):463-71

9. Eom JW1, Lim YJ2, Kim MJ3, Kwon HB4. Three-dimensional finite element analysis of implant-assisted removable partial dentures J Prosthet Dent. 2017 Jun;117(6):735-742

10. Sato Y, Tsuga K, Abe Y, Akagawa Y. Finite element analysis of the effect of vertical curvature on half oval cast clasps. J Oral Rehabilit 1999; 26:554-558.

11. Yang, Lang, Felton. Finite element stress analysis on the effect of splitting in fixed partial dentures. J Prosthet Dent 1999; 81(6): 721-728
12. O'Grady J, Sherif M, Likeman P. A finite element analysis of a mandibular canine as a denture abutment. Eur J Prosthodontic Rest. Dent 1996; 4(3): 117-121.

13. Craig G. Restorative dental materials. Tenth edition. Mosby. 1997.

14. Aleksandar Todorovi, Katarina Radovi, Aleksandar Grbovi, Rebeka Rudolf, Ivana Maksimovi, Dragoslav Stamenkovi” STRESS ANALYSIS OF A UNILATERAL COMPLEX PARTIAL DENTURE USING THE FINITE-ELEMENT METHOD” j materia\&technology 2010;(1)41-47.

15. Jafar Gharechahi, Esmael Sharifi, Saeid Nosohian, Nafiseh Asadzadeh Aghdaee" Finite Element Method Analysis of Stress Distribution to Supporting Tissues in a Class IV Aramany Removable Partial Denture (Part II: Bone and Mucosal Membrane"The Journal of Contemporary Dental Practice, 2008(9), 7.

16. Verri FR1, Pellizzer EP, Pereira JA, Zuim PR, Santiago Júnior JF. Evaluation of bone insertion level of support teeth in class I mandibular removable partial denture associated with an osseointegrated implant: a study using finite element analysis Implant Dent. 2011 Jun;20(3):192201

17. Ralph w. and Williams F. Analysis of stresses in alveolar bone-A two dimensional photo-elastic model .Arch Oral Biol. 1975;20:411-14.

18. Asundi A. and Kishen A. A strain gauge and photoelastic analysis of in vivo strain and in vitro stress distribution in human dental supporting structures. Arch Oral Bio. 2000; 45:543-550.

19. Mustafa Fayad 2010 Partial denture theory and practice $\mathrm{p} 153$

20. Nakamura Y1, Kanbara R2, Ochiai KT3, Tanaka Y4. A finite element evaluation of mechanical function for 3 distal extension partial dental prosthesis designs with a 3-dimensional nonlinear method for modeling soft tissue.J Prosthet Dent. 2014 Oct;112(4):972-80 